\title{
Accumulation of Lipochitin Oligosaccharides and NodD-Activating Compounds in an Efficient Plant-Rhizobium Nodulation Assay
}

\author{
Teun Tak, Paulina C. van Spronsen, Jan W. Kijne, Anton A. N. van Brussel, and Kees J. M. Boot \\ Institute of Biology Leiden, Clusius Laboratory, Leiden University, Wassenaarseweg 64, 2333 AL Leiden, The Netherlands
}

Submitted 8 August 2003. Accepted 14 February 2004.

\begin{abstract}
During legume plant-Rhizobium spp. interactions, leading to the formation of nitrogen-fixing root nodules, the two maor determinants of host plant-specificity are plant-produced nod gene inducers (NodD protein activating compounds) and bacterial lipochitin oligosaccharides (LCOs or Nod factors). In a time course, we describe the accumulation of LCOs in an efficient nodulation assay with Vicia sativa subsp. nigra and Rhizobium leguminosarum, in connection with the presence of NodD-activating compounds in the exudate of $V$. sativa roots. Relatively small amounts of both LCOs and NodD-activating compounds were found to be required for initiation of nodulation during the first days after inoculation. A strong increase in the amount of NodRIv-V[18:4,Ac] LCOs preceded root infection and nodule primordium formation. In contrast to the situation with non-nodulating rhizobia and nonmitogenic LCOs, the amount of NodD-activating compounds in the culture medium remained small after addition of nodulating rhizobia or mitogenic LCOs. Furthermore, addition of nodulating rhizobia or mitogenic LCOs resulted in nearly complete inhibition of root hair formation and elongation, whereas nonmitogenic LCOs stimulated root hair growth. Retention of NodD-activating compounds in the root may inhibit root hair growth.
\end{abstract}

Bacteria belonging to the family Rhizobiaceae (collectively called rhizobia) can induce the formation of nitrogen-fixing nodules on roots of legume plants. During this symbiotic interaction, host-plant specificity is obtained by mutual signaling. A plant-specific mixture of secreted flavonoids triggers biosynthesis of Rhizobium spp.-produced lipochitin oligosaccharides (LCOs or Nod factors). Depending on their structure, these LCOs are responsible for induction of root nodule formation on a certain set of host legumes (Stougaard 2000). Genes involved in synthesis and secretion of LCOs are under control of the regulatory NodD protein or proteins, which functions as a transcriptional activator of nod (nodulation) genes containing a nod box sequence. Probably, activation of NodD occurs after binding of a specific flavonoid (Schlaman et al. 1998). For instance, for alfalfa, luteolin was found to be an active flavonoid involved in production of Sinorhizobium meliloti LCOs (Peters et al. 1986); whereas, for white clover, two main inducers were found to be 7,4'-dihydroxyflavone and geraldone (Redmond et al. 1986). For Vicia sativa, another two nod gene inducers have been identified, namely $3,5,7,3^{\prime}-$

Corresponding author: Kees J. M. Boot; Fax: 31-71-5274999; E-mail: boot@ rulbim.leidenuniv.nl tetrahydroxy-4'-methoxyflavanone and 7,3'-dihydroxy-4'-methoxyflavanone (Zaat et al. 1989a). Notably, all these inducers were isolated from sterile seed or plants that had not been in contact with rhizobia.

Recourt and associates (1991) found that, in contrast to sterile $V$. sativa roots, roots inoculated with Rhizobium leguminosarum bv. viciae exuded additional NodD-activating flavonoids. The flavonoid with the largest activity toward NodD of $R$. leguminosarum bv. viciae was 7,3'-dihydroxy-4'-methoxyflavanone; levels increased approximately 10-fold compared with those in sterile root exudate. However, these inducers were identified from root exudates of plants with roots grown in the light in the absence of the ethylene-biosynthesis inhibitor aminoethoxyvinylglycine (AVG). After inoculation with rhizobia, such roots develop the thick short root (Tsr) phenotype, resulting in delayed nodulation on lateral roots (van Brussel et al. 1982, Zaat et al. 1989b). Furthermore, in these experiments, root exudates were analyzed 7 days after inoculation with $R$. leguminosarum bv. viciae, leaving data about the presence of NodD-activating flavonoids at earlier phases of the interaction unrevealed.

The first LCOs the structure of which was determined were those from S. meliloti (Lerouge et al. 1990). Later, it was found that the structures of LCOs of all rhizobia analyzed have a lot in common (Downie 1998). They usually consist of a backbone of four or five $\beta$-1,4-linked $N$-acetyl-D-glucosamine residues, with a fatty acid attached to the nonreducing end and with various substitutions at the reducing or nonreducing sugars. Usually, LCOs are isolated from bacterial cultures grown in liquid growth medium with a high concentration of an LCO production-inducing flavonoid. In these experiments, culture medium, growth temperature, and amounts of LCO production-inducing flavonoids all are different from the conditions during a regular nodulation assay.

To our knowledge, isolation and determination of LCOs in connection to characterization of nod gene-inducing activity have not been performed yet with use of normal nodulation conditions. Recently, we described an in vitro test system to study the symbiosis between $V$. sativa subsp. nigra and $R$. leguminosarum (Van Spronsen et al. 2003). In this system, plants are grown in dark pots (with roots shielded from light) containing liquid Jensen medium buffered at $\mathrm{pH} 5.6$ and supplemented with AVG. With use of this system, very rapid and reproducible nodulation could be obtained. We used this assay to isolate LCOs that are produced during the first days after inoculation of $V$. sativa with $R$. leguminosarum. Furthermore, we determined the accumulation of NodD-activating compounds during the initial phase of nodule formation in this system. 


\section{RESULTS}

Time course of nodulation.

$V$. sativa subsp. nigra plants were grown on dark pots containing buffered liquid Jensen medium supplemented with AVG. Root growth occurred at approximately $1.5 \mathrm{~cm}$ per day. One day after inoculation with the nodulating $R$. leguminosarum RBL 5523, root hair deformations could be observed, which intensified after 2 days in the form of swellings and branching, mostly at newly formed hairs at the upper part of the root. After 3 days, curled root hairs containing infection threads and primordia that were clearly visible as "bumps" could be observed. Four days after inoculation, the nodule primordia were well developed. Nodules were formed mostly close together or clustered, and were situated at the upper part of the root. All together, it appeared that the whole nodulation process of attachment, root hair deformation, infection thread formation, and nodule primordia formation occurred within the first 3 days after inoculation.

\section{LCOs formed during rhizobia-plant interaction.}

$V$. sativa plants were grown in the presence of $R$. leguminosarum $\mathrm{RBL} 5523$ with radiolabeled ${ }^{14} \mathrm{C} \mathrm{N}$-acetyl-glucosamine added to the culture medium. The medium was sampled 24, 48, and $72 \mathrm{~h}$ after addition of the bacteria, and extracted with n-butanol as described earlier (Spaink et al. 1991, 1992). Labeled LCOs were analyzed using reversed-phase thin-layer chromatography (TLC) (Spaink et al. 1991, 1992). As a control, R. leguminosarum RBL 5523 was grown in $\mathrm{B}^{-}$ medium with ${ }^{14} \mathrm{C}$-labeled $\mathrm{N}$-acetyl-glucosamine and with naringenin as a nod gene-inducer for $18 \mathrm{~h}$ at either $28^{\circ} \mathrm{C}$ or $20^{\circ} \mathrm{C}$. $n$-Butanol extracts from these cultures were run on TLC plates for comparative analysis.

During the first $24 \mathrm{~h}$ after inoculation, relatively small amounts of LCOs were being formed. Only one spot became visible after prolonged exposure (Fig. 1A). This spot is the same as the mixed spot seen in bacterial extracts that represents both NodRlv-IV[18:4,Ac] and NodRlv-V[18:1,Ac] (Fig. $1 \mathrm{C}$, spot 2). After $48 \mathrm{~h}$, a strong increase in the amount of
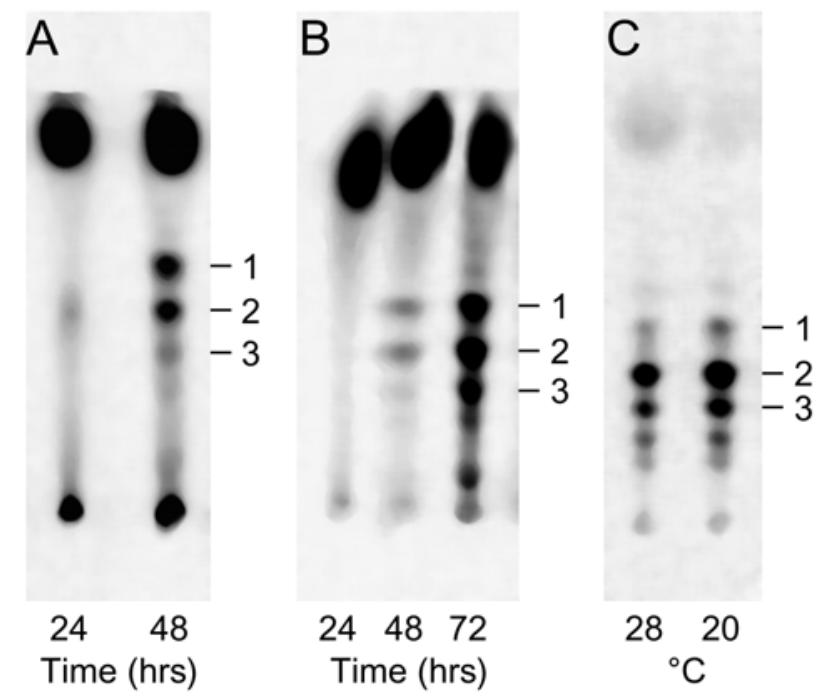

Fig. 1. Thin-layer chromatography analysis on octadecyl silica plates of $\mathbf{A}$ and $\mathbf{B}$, lipochitin oligosaccharides (LCOs) produced after inoculation of Vicia sativa subsp. nigra plants with Rhizobium leguminosarum RBL 5523 and of $\mathbf{C}$, LCOs produced by $R$. leguminosarum RBL 5523 grown on $\mathrm{B}^{-}$ medium A, during the first 24 and $48 \mathrm{~h}$ (shown after prolonged exposure); B, after 24,48 , and $72 \mathrm{~h}$; and $\mathbf{C}$, after $18 \mathrm{~h}$ at either 28 or $20^{\circ} \mathrm{C}$. LCOs are indicated as follows: $1=$ NodRlv-V[18:4,Ac], $2=$ NodRlv-IV [18:4,Ac] and NodRlv-V[18:1,Ac], and $3=$ NodRlv-IV [18:1,Ac].
NodRlv-V[18:4,Ac] (Fig. 1A, spot 1) could be observed, together with an increase in the mixed spot of both LCOs (Fig. 1A, spot 2). Also, a weak spot representing NodRlvIV[18:1,Ac] now could be seen (Fig. 1A, spot 3). Incubation for $72 \mathrm{~h}$ resulted in a strong increase in the amount of all types of LCOs (Fig. 1B). Furthermore, the identity of LCOs in the medium was determined by liquid chromatography-mass spectrometry (LC-MS) and matrix-assisted laser desorptonionization-time of flight-MS analysis. We found LCOs only with the expected predicted structures, NodRlvIV/V[18:4,AC] and NodRlv-IV/V[18:1,AC], with amounts that corresponded to those observed on TLC plates (data not shown).

Comparison of these results with rhizobial LCOs that are produced in a batch culture in $\mathrm{B}^{-}$medium is difficult due to the different culture methods and number of bacteria present in the inoculums. Both at 28 and at $20^{\circ} \mathrm{C}$, all different types of LCOs are produced already after $18 \mathrm{~h}$ (Fig. 1C). Interestingly, the spot representing NodRlv-V[18:4,Ac] is relatively small compared with the two other spots (Fig. 1C, spot 1).

After $72 \mathrm{~h}$ of incubation, LCO spots that appeared below spot 3 (Fig. 1B) could be identified. To characterize these spots, we used a different TLC analysis. The results of prolonged incubation of $V$. sativa plants with $R$. leguminosarum RBL 5523 in the presence of labeled glucosamine for 72 and $96 \mathrm{~h}$ is shown in Figure 2. After $96 \mathrm{~h}$, spots of smaller LCOs appeared. In particular, LCOs consisting of two and three glucosamine residues were being found, presumably representing breakdown products (Fig. 2, spots II and III). Their presence did not coincide with a corresponding decrease in the amount of NodRlv LCOs consisting of four and five glucosamine residues.

In conclusion, the amount of LCOs that is formed under efficient nodulation conditions is largest at day 3 of plantbacteria interactions. Smaller LCOs, possibly representing breakdown products, can be seen from day 4. Enhanced accumulation of mitogenic NodRlv-IV/V[18:4,Ac] LCOs at day 2 shortly precedes induction of formation of root nodule primordia, being clearly visible at day 3 .

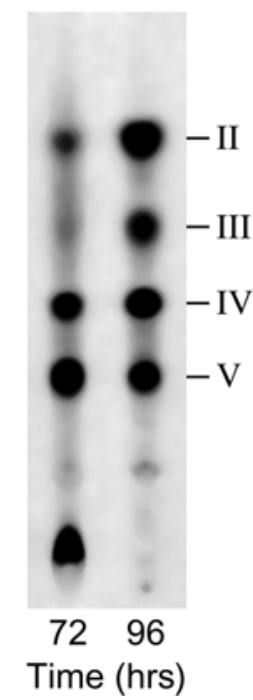

Fig. 2. Thin-layer chromatography analysis on silica 60 plates of lipochitin oligosaccharides (LCOs) produced after inoculation of Vicia sativa subsp. nigra plants with Rhizobium leguminosarum RBL 5523 for 72 and 96 h. Roman numerals indicate the migration positions of LCOs consisting of two (II), three (III), four (IV), or five (V) GlcNac residues. Presumable breakdown products of LCOs consisting of two and three GlcNac containing residues start to appear $72 \mathrm{~h}$ after inoculation and increase in amount after $96 \mathrm{~h}$, without affecting the amount of four- and five-GlcNac types of LCOs. 
Role of the ratio of mitogenic and nonmitogenic LCOs in primordium formation.

Mitogenic NodRlv-IV/V[18:4,Ac] appeared to be simultaneously present with nonmitogenic NodRlv-IV/V[18:1,Ac] LCOs; therefore, we wondered whether nonmitogenic LCOs interfere with the nodulation process. Thus, we studied the effect of simultaneously adding both types of LCOs at different concentrations to $V$. sativa plants, in order to determine the effect on nodule primordia formation. Simultaneous addition of equimolar

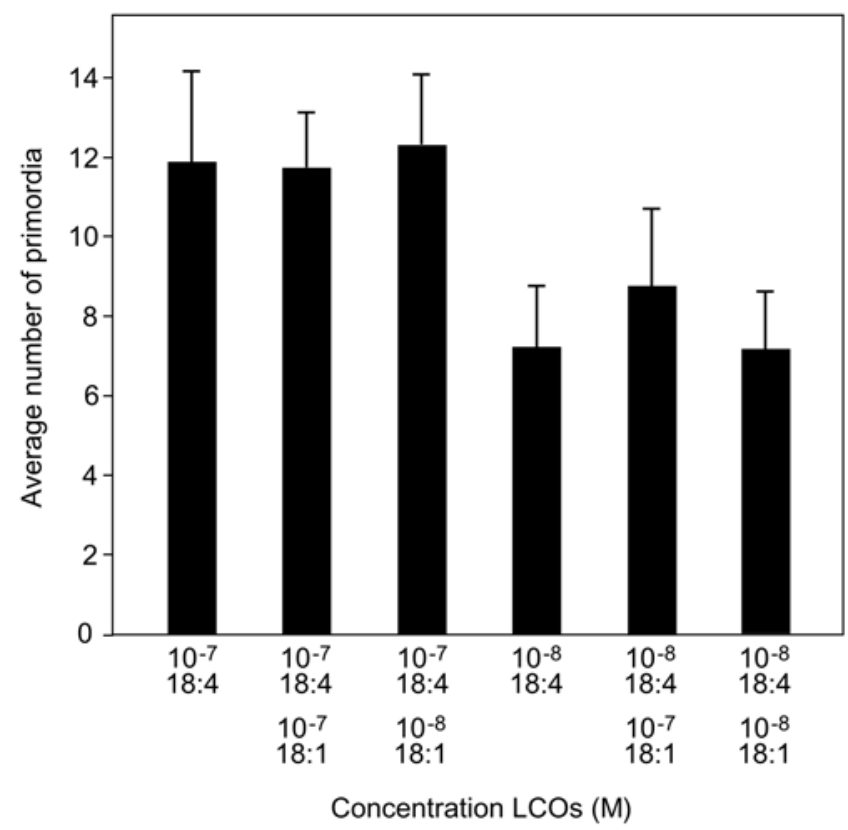

Fig. 3. Development of nodule primordia after treatment of Vicia sativa roots with mitogenic NodRlv-IV/V[18:4,Ac], nonmitogenic NodRlvIV/V[18:1,Ac], or both lipochitin oligosaccharides (LCOs) at different concentrations. Bars indicate standard deviation. amounts of both LCOs yielded a number of primordia identical to that induced by mitogenic LCOs only (Fig. 3). Similar results were obtained after mixing mitogenic LCOs with a 10-times smaller amount of nonmitogenic LCOs. However, addition of a 10-times larger amount of nonmitogenic LCOs at $10^{-7}$ to a $10^{-8}$ $\mathrm{M}$ amount of mitogenic LCOs consistently increased the number of primordia that are formed compared with the number formed by adding only $10^{-8} \mathrm{M}$ of mitogenic LCOs. This might indicate that the ratio of nonmitogenic and mitogenic LCOs can be an important factor during nodulation. In our nodulation assay, mitogenic and nonmitogenic LCOs appeared to be present in the same order of magnitude. At any rate, presence of nonmitogenic LCOs does not seem to inhibit initiation of nodulation.

\section{NodD-activating compounds formed during plant-rhizobia interactions.}

In order to determine nodulation gene-inducing activity of root exudates of $V$. sativa plants grown in the absence or presence of different bacterial strains, we used $R$. leguminosarum RBL 5280, which contains the regulatory nodD gene together with the inducible nodA promoter fused to the Escherichia coli lacZ gene (Spaink et al. 1987a). Root medium was harvested at $1,2,3,4$, and 7 days after inoculation of $V$. sativa plants with either $R$. leguminosarum LPR 5045 (a Sym-plasmidcured strain without nod genes) or $R$. leguminosarum RBL 5523 , and from uninoculated control roots. To be able to compare several independent experiments, the $\beta$-galactosidase activity was expressed as a percentage of the luteolin-induced (control) activity that was set at $100 \%$ ( $\beta$-galactosidase activity luteolin $23.997 \pm 7,201$ units, $n=10$ ).

The amount of NodD-activating compounds in the root medium was largest at days 3 and 4 in the uninoculated control and in root medium from plants inoculated with $R$. leguminosarum LPR 5045 (Fig. 4). After 7 days, a relatively large amount of activators appeared to be present in root exudates of these plants. In contrast, in root exudates from plants inoculated with the nodulating $R$. leguminosarum RBL 5523 , a relatively weak induction of NodD activity was found

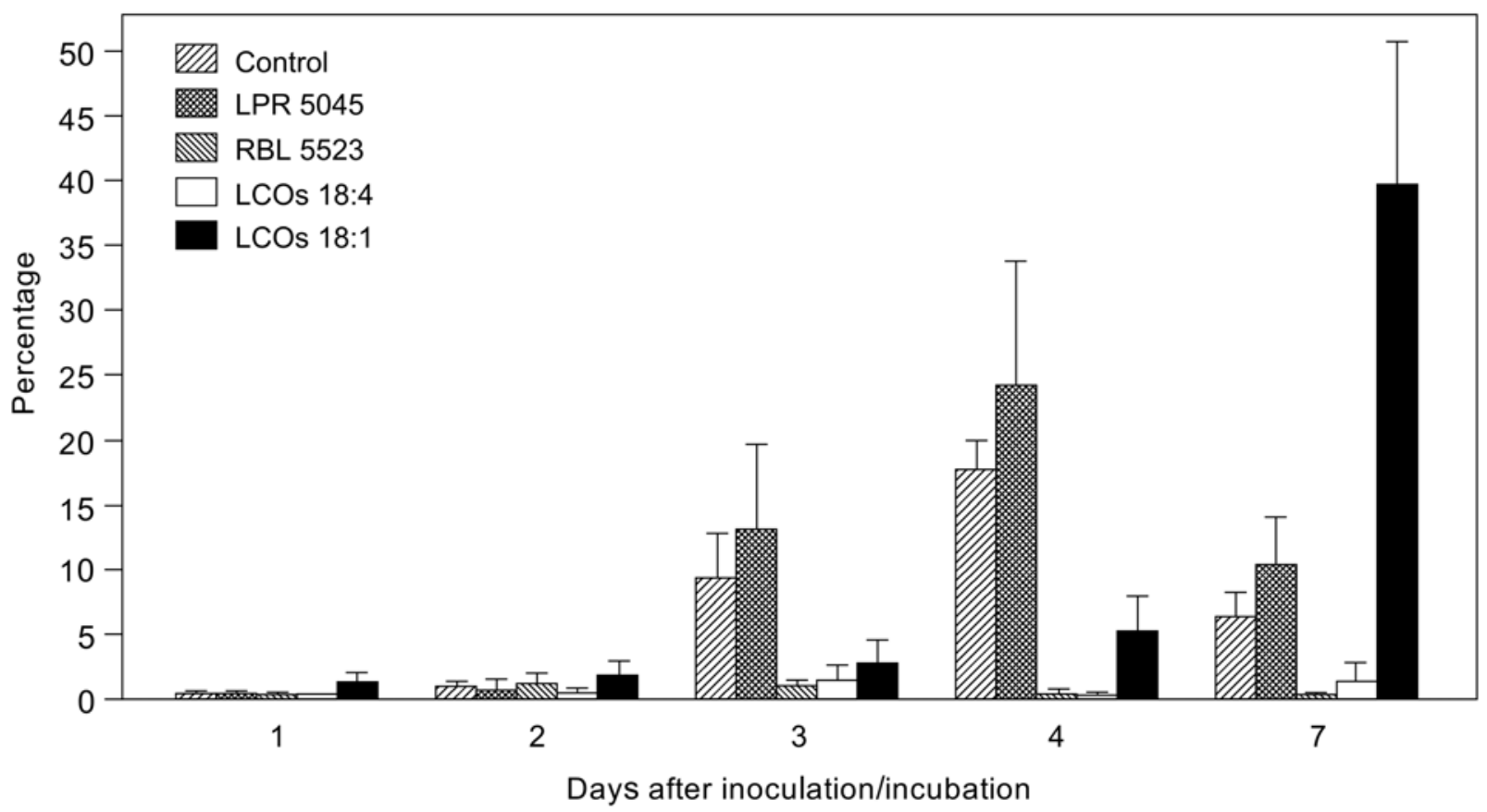

Fig. 4. Time course of accumulation of NodD-activating compounds present in the exudates of Vicia sativa subsp. nigra plants after different treatments. Plants were inoculated at day 0 with either Rhizobium leguminosarum RBL 5523 or LPR 5045, or purified lipochitin oligosaccharides (LCOs) NodRlvIV/V[18:4,Ac] or NodRlv-IV/V[18:1,Ac] at a final concentration of $10^{-7} \mathrm{M}$ or without any addition as a control. The $\beta$-galactosidase activity was expressed as a percentage of the luteolin-induced activity that was set at $100 \%$. Bars indicate standard deviation. 
throughout the sampling period. In comparison with root exudates from uninoculated controls or plants inoculated with $R$. leguminosarum LPR 5045, accumulation of NodD inducers at days 3 and 4 appeared to be inhibited (Fig. 4). This observation contrasts previous work from Recourt and associates (1991), who found that inoculation with infective $R$. leguminosarum bacteria largely increased the NodD-activating ability of $V$. sativa root exudates. Because these experiments yielded an aberrant nodulation phenotype, one can conclude that roots grown in the light in absence of AVG (which results in the Tsr phenomenon and delayed nodulation) respond in an aberrant way to mitogenic LCOs.

$R$. leguminosarum RBL 5523 inhibited the accumulation of nod gene-inducing activity in root exudates; therefore, we tested whether purified LCOs have the same effect. Purified mitogenic NodRlv-IV/V[18:4,Ac] LCOs and nonmitogenic NodRlv-IV/V[18:1,Ac] LCOs, both at a final concentration of $10^{-7} \mathrm{M}$, were added to the plant roots. Both types of LCOs, but especially the mitogenic LCOs, inhibited the accumulation of NodD activators in root exudates during the first 4 days compared with controls and $R$. leguminosarum LPR 5045-inoculated roots (Fig. 4). However, 7 days after addition of the nonmitogenic LCOs, a very strong increase in NodD activation was observed, in contrast to the situation after addition of mitogenic LCOs (Fig. 4). We obtained similar results by using a strain containing the inducible nod $F$ promoter fused to the lacZ gene (K. J. M. Boot, unpublished data).

From these experiments, we can conclude that a relatively small amount of NodD-activating compounds in root exudate, such as is present at days 1 and 2, is sufficient for triggering LCO production. Furthermore, under efficient nodulation conditions, both infective rhizobia and purified mitogenic LCOs inhibit accumulation of NodD-activating compounds in the culture medium.

\section{Importance of the amount}

\section{of NodD-activating compounds for nodulation.}

In a subsequent set of experiments, we tested whether the amount of NodD-activating compounds that is present at a certain time point can influence the nodulation process. Therefore, we measured the average number of primordia or nodules formed after adding $R$. leguminosarum RBL 5523 in a time course from 0 to 4 days. We observed increased nodulation when rhizobia were added at day 3 or 4 after the start of seedling culture (nodule number at days 1 and 2 was 9 and 12, respectively; nodule number at days 3 and 4 was 14 and 13, respectively). This suggests a positive correlation between nodulation success and the presence of NodD-activating compounds in the exudate. However, repetition of the experiment with use of $R$. leguminosarum RBL 5561 pMP604, a flavonoid-independent transcription activation (FITA) nodD strain, yielded results similar to those obtained with the flavonoid-dependent $R$. leguminosarum RBL 5523. This shows that the increased amount of NodD-activating compounds present at days 3 and 4 is not responsible for the observed increase in nodule formation. Other factors, such as, for example, root growth, might be more important in this respect.

\section{Different effects of bacteria and LCOs on root hair growth.}

Roots of germinated seed of $V$. sativa subsp. nigra have an emerging root hair zone. After the plants were put on liquid medium and grown for several days, this root hair zone (indicated as the old root hair zone) remained mostly unchanged at the upper part of the root and had an identical appearance in all used assays. In control roots, a new emerging root hair zone developed lower on the roots approximately $1.5 \mathrm{~cm}$ above the root tip. After inoculation, however, a large difference in development of root hairs could be observed depending on which bacteria or LCOs were added. A series of 6-day-old root parts from a region just below the zone of lateral root emergence is shown in Figure 5. This region is representative of the remaining lower part of the roots up to approximately $1.5 \mathrm{~cm}$ above the tip. Control roots had many hairs distributed over the entire root (Fig. $5 \mathrm{~A})$. Most of these hairs were rather long and slightly wavy (Fig. 6A), but not branched or swollen. Roots inoculated with the nonnodulating $R$. leguminosarum LPR 5045 developed root hairs that were similar in amount and appearance to those of control roots (Figs. 5B and 6B). However, roots inoculated with the nodulating $R$. leguminosarum RBL 5523 showed an almost complete prevention of the formation of new root hairs (Fig. 5C). Only at close observation could very young root hairs be found after 6 days (Fig. 6C). Addition of purified mitogenic NodRlv-IV/V[18:4,Ac] LCOs at a concentration of $10^{-7} \mathrm{M}$ also prevented the formation of root hairs (Figs. 5D and 6D), with only a few (cortical) hairs present on top of the primordia (Fig. 5D) but not on the roots. In contrast, addition of the nonmito-
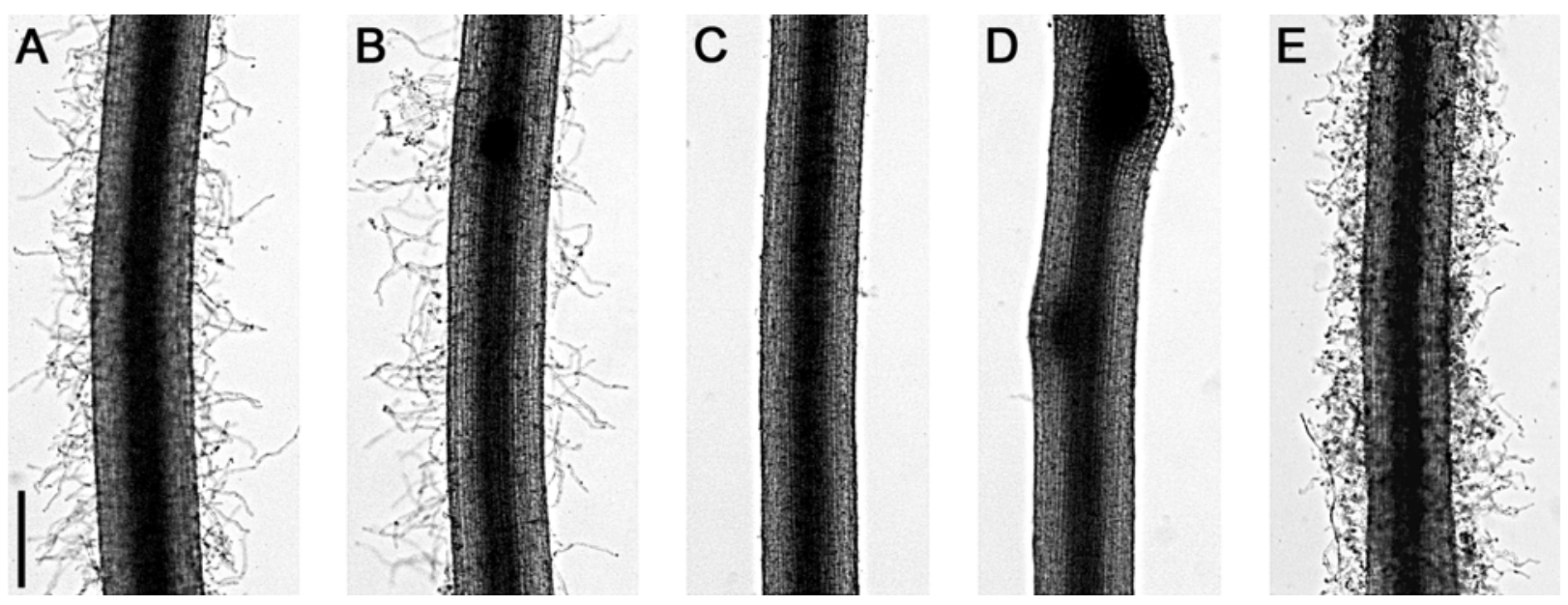

Fig. 5. Light micrographs of 6-day-old Vicia sativa subsp. nigra roots. The parts that are shown are from a region just below the zone of lateral root emergence and are representative for the remaining lower root parts to about $1.5 \mathrm{~cm}$ above the tip. Bar $=500 \mu \mathrm{m}$. A, Control: many hairs distributed over the entire root. B, Inoculated with the nonnodulating Rhizobium leguminosarum LPR 5045: development of root hairs is similar to controls. C, Inoculated with the nodulating $R$. leguminosarum RBL 5523: an almost complete inhibition of root hair formation. D, Incubated with mitogenic NodRlv-IV/V[18:4,Ac] lipochitin oligosaccharides (LCOs): a complete inhibition of root hair formation, only some (cortical) root hairs are visible on top of primordia. E, Incubated with nonmitogenic NodRlv-IV/V[18:1,Ac] LCOs: an abundant increase in root hair formation and deformation. 
genic NodRlv-IV/V[18:1,Ac] LCOs at a concentration of $10^{-7}$ $M$ resulted in a large increase in root hair formation, especially after 6 to 7 days (Fig. 5E). These root hairs were curly, branched, and occasionally swollen (Fig. 6E). The inhibitory effect of mitogenic NodRlv-IV/V[18:4,Ac] LCOs on root hair growth also was visible at lower concentrations of $10^{-8}$ and even at $10^{-9} \mathrm{M}$ (data not shown). Addition of a 10-fold or even 100fold excess of nonmitogenic NodRlv-IV/V[18:1,Ac] LCOs at these lower concentrations of mitogenic LCOs did not result in an increase of root hair growth. This shows that the inhibitory effect of the mitogenic LCOs overrules the stimulating effect of the nonmitogenic LCOs on root hair growth.

These results demonstrate that, after nodule formation in the old root hair zone induced by nodulating bacteria, the formation of new root hairs on younger parts of the roots is nearly completely prevented. Also, addition of mitogenic LCOs prevents the formation of root hairs below the old root hair zone. This inhibitory effect is correlated with the persistently inhibitory effect of mitogenic rhizobia and LCOs on accumulation of NodD-activating compounds in the root exudate.

\section{DISCUSSION}

In this study, we describe a time course of accumulation of LCOs with use of a well-defined and efficient Rhizobium spp.-legume nodulation assay. In earlier publications, production of LCOs was described as monitored after growth of bacterial cultures in the presence of relatively large amounts of nod gene inducers or, at best, after induction with root extracts or root exudates. Furthermore, growth conditions, medium composition, and growth temperature of the bacteria during LCO production each were different from the situation during normal plant-rhizobia interactions. Recently, we described a very reproducible and fast nodulation system in which the process of nodulation during interactions of $V$. sativa subsp. nigra and R. leguminosarum can be studied using well-defined and controlled growth conditions for both plants and bacteria (Van Spronsen et al. 2003). In this system, nodule formation takes place within the first 3 days after inoculation, which implies that all initial aspects of nodulation, such as root hair deformation, attachment, root hair curling, infection thread formation, formation of nodule primordia, and induction of autoregulation, occur within this short time period. Only maturation of nodules as well as nitrogen fixation take place at later stages. Using this nodulation system, we studied both the accumulation of LCOs during the initial phases of plant-rhizobia interactions and the presence of NodD-activating compounds in the root exudates of the plants.

We could detect relatively small amounts of a specific set of LCOs during the first 2 days after inoculation. At 3 and 4 days after inoculation, larger amounts of all different types of LCOs could be observed. This suggests that the whole nodulation process needs relatively small amounts of LCOs because, at
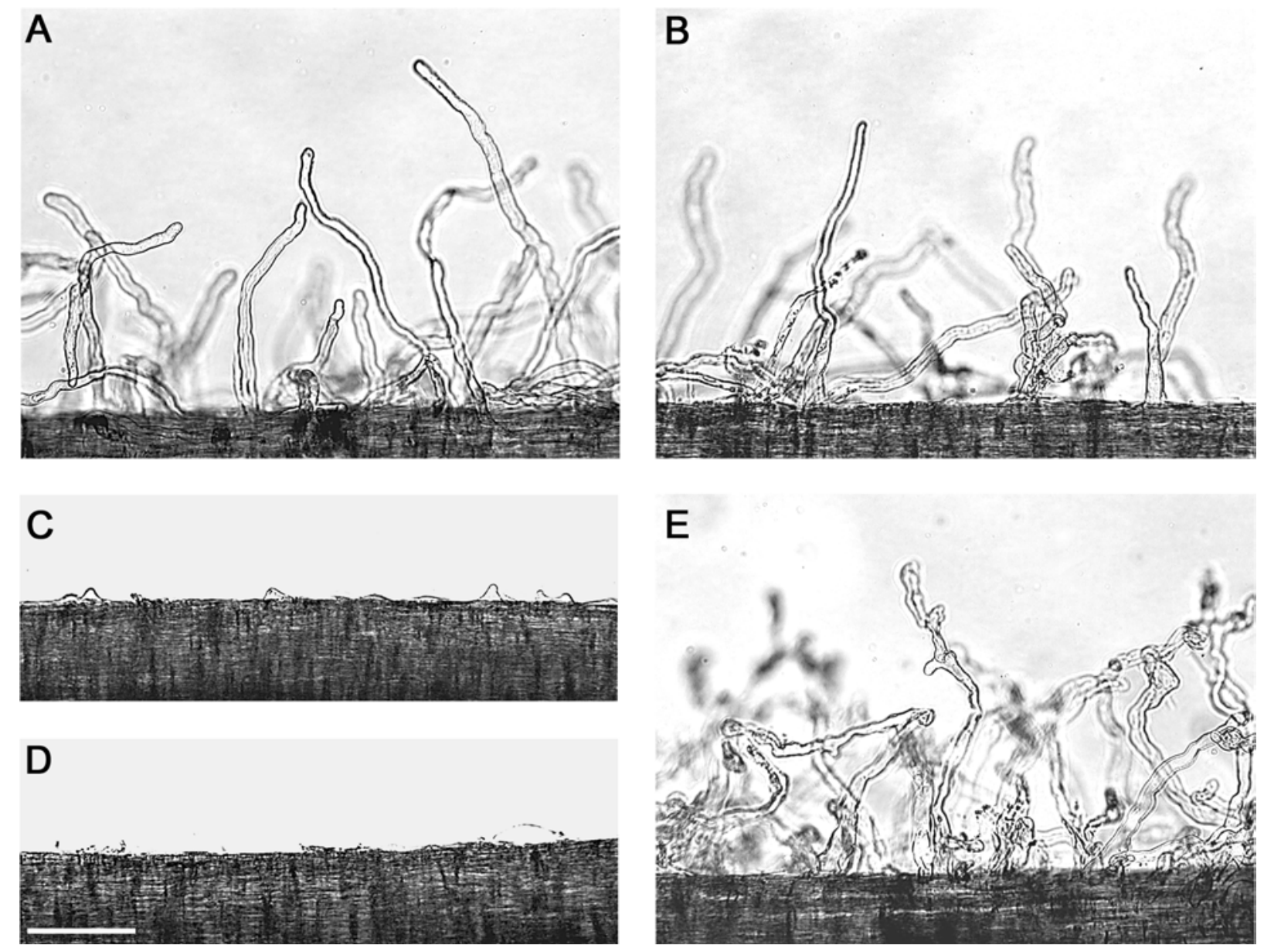

Fig. 6. Detailed light micrographs of root hairs from a region just below the zone of lateral root emergence. Bar $=100 \mu \mathrm{m}$. A, Control: root hairs are long and slightly wavy. B, Inoculated with the nonnodulating Rhizobium leguminosarum LPR 5045: root hairs are similar to controls. C, Inoculated with the nodulating $R$. leguminosarum RBL 5523: only some very young root hairs can be found. D, Incubated with mitogenic NodRlv-IV/V[18:4,Ac] lipochitin oligosaccharides (LCOs): complete inhibition of root hair formation; only some detached epidermal cells can be observed. E, Incubated with nonmitogenic NodRlv-IV/V[18:1,Ac] LCOs: increased numbers of curly, branched and occasionally swollen root hairs. 
day 3 , the initial process of nodule formation already has been completed. Exact quantification of LCO concentrations minimally required for root infection and nodulation will be meaningful only when it is possible to determine LCO concentrations at the site of attachment of rhizobia to the root hairs, rather than in culture medium. Compared with bacterial cultures, the amount of NodRlv-V[18:4,Ac]-type LCOs was relatively larger in the plant growth medium during plantrhizobia interactions. This is significant because this type of LCO, together with the NodRlv-IV[18:4,Ac] type, is responsible for induction of the formation of nodule primordia. A strong increase in the amount of NodRlv$\mathrm{V}[18: 4, \mathrm{Ac}]$ preceded root infection and nodule primordium formation. Presumable breakdown products of LCOs only were observed 4 days after inoculation, without affecting to a large degree the amount of intact LCOs. This is contrary to the situation in alfalfa, where addition of nodulating Sinorhizobium strains to plants induced the activity of a dimerforming enzyme which already could cleave the NodRmIV(S) LCOs after $19 \mathrm{~h}$ (Staehelin et al. 1995). Addition of purified LCOs to alfalfa plants could induce the activity of this enzyme after a few hours. However, the amount of LCOs needed to induce the activity of the cleaving enzyme in alfalfa was relatively large, approximately $10^{-7} \mathrm{M}$. Possibly, the concentration of LCOs required for induction of a similar enzyme in our nodulation assay was reached only after 3 to 4 days of culture.

Earlier, our group reported that addition of nodulating strains of rhizobia to $V$. sativa roots resulted in biosynthesis and enlarged accumulation of novel NodD-activating compounds (Recourt et al. 1991). With the present assay, we found accumulation of NodD-activating compounds to be inhibited by mitogenic rhizobia and LCOs. The difference between these results can be explained by the difference in growth conditions. Zaat and associates (1989a) and Recourt and associates (1991) grew the vetch plants with roots in the light in the absence of the ethylene-biosynthesis inhibitor AVG, which resulted in the Tsr phenotype with a delayed and aberrant nodulation pattern. The Tsr phenotype is characterized by excessive ethylene formation and root deformation. Tsr roots may excrete flavonoids, which normally are retained in the root tissue. To our knowledge, only one other group reported a decrease in flavonoid content in root exudates. After inoculation of soybean roots with the nodulating $S$. fredii USDA257S1, a strong reduction in the amount of daidzein was observed after $48 \mathrm{~h}$ (Pueppke et al. 1998). This result may be indicative for the efficiency of the nodulation assay used. At present, we cannot distinguish between several explanations for the observed inhibition of accumulation of NodDactivating compounds. These compounds may be degraded, conjugated, or retained by the roots, or their biosynthesis may be inhibited. However, we can exclude the possibility that inhibitors of nod gene expression are being formed, because exudates from roots inoculated with $R$. leguminosarum RBL 5523 or treated with mitogenic LCOs did not decrease induction of the $\operatorname{nodA}$ promoter when mixed with active control exudates from untreated controls or $R$. leguminosarum LPR 5045-treated plants (A. A. N. van Brussel, unpublished data). In the absence of LCOs, vetch root exudates showed an increase in the amount of NodD-activating compounds. This enlarged accumulation may function in stimulation of rhizobial chemotaxis toward the nitrogen-deficient plant roots (Armitage et al. 1988).

Apparently, very low concentrations of NodD-activating compounds are sufficient for induction of nod gene expression. We estimate the amounts of NodD-activating compounds present during the first days after inoculation with $R$. leguminosarum RBL 5523 or mitogenic LCOs to be in the range of a few nanomolar, as judged from the fact that halfmaximal induction of the $\operatorname{nodA}$ promoter with luteolin was observed at $40 \mathrm{nM}$ (Zaat et al. 1987). Currently, we are in the process of isolation and characterization of the NodDactivating compounds present in root exudates.

Another interesting and novel observation concerned the differential effect of rhizobial strains and LCOs on root hair formation and growth. Nodulating rhizobia and mitogenic LCOs strongly inhibited formation and elongation of new root hairs, whereas nonmitogenic LCOs stimulated the formation of hairs compared with control roots, as was suggested before by van Brussel and associates (1992). The stimulating effect of NodRlv-IV/V[18:1,Ac] was most notable 6 to 7 days after addition to the roots. Interestingly, the differential effect of rhizobial strains and LCOs on root hair formation and growth was correlated with the same differential effect on accumulation of NodD-activating compounds. It is possible that the reduction of effective root surface due to the lower amount of root hairs could be responsible for the decrease in the excretion of NodDactivating compounds. Another possible explanation for inhibition of root hair growth together with inhibition of accumulation of NodD-activating compounds in the culture medium can be based on accumulation of NodD-activating compounds in root hairs or root hair-forming epidermal cells. Root hair development in Arabidopsis spp. is well-studied, and can be divided into several steps (Mathur and Hülskamp 2001). The initial step is epidermal cell specification, followed by root hair initiation and, finally, root hair elongation by tip growth. For the last two steps, hormones and environmental factors are important factors (Cho and Cosgrove 2002; Rahman et al. 2002). The two plant hormones auxin and ethylene that influence root hair initiation and elongation also have been implicated as being involved in

Table 1. Bacterial strains and their relevant characteristics

\begin{tabular}{|c|c|c|}
\hline Strain & Relevant characteristics & References \\
\hline \multicolumn{3}{|c|}{ Rhizobium spp. } \\
\hline 248 & R. leguminosarum bv. viciae wild type containing Sym plasmid pRL1JI & Josey et al. 1979 \\
\hline RBL 5515 & R. leguminosarum bv. trifolii $\mathrm{RCR} 5$ cured of its own Sym plasmid $\operatorname{Str}^{\mathrm{r}} \operatorname{Rif}^{\mathrm{r}}$ & Priem and Wijffelman 1984 \\
\hline RBL 5523 & RBL 5515 with Sym plasmid pRL1JI::Tn1831 derived from R. leguminosarum bv. viciae $\operatorname{Str}^{\mathrm{r}} \operatorname{Rif}^{\mathrm{r}}{ }^{\mathrm{Sp}} \mathrm{c}^{\mathrm{r}}$ & $\begin{array}{l}\text { Pees et al. 1986, } \\
\text { Van Workum et al. } 1998\end{array}$ \\
\hline LPR 5045 & R. leguminosarum bv. trifolii RCR5 cured of its own Sym plasmid Rif ${ }^{r}$ & Hooykaas et al. 1982 \\
\hline RBL 5561 & LPR 5045 with Sym plasmid pRL1JI nodD2::Tn5 Rif2 ${ }^{\mathrm{r}}$ & Zaat et al. 1987 \\
\hline RBL 5280 & LPR 5045 (pMP 280, pMP 154) Rif2 ${ }^{\mathrm{r}}$ & Spaink et al. 1987a,b \\
\hline \multicolumn{3}{|l|}{ Plasmids } \\
\hline pMP 604 & IncP $\mathrm{Tc}^{\mathrm{r}}$ contains nodD FITA (flavonoid independent transcription activation) & Spaink et al. 1989 \\
\hline pMP 154 & $\begin{array}{l}\text { R. leguminosarum promoter nodABCIJ-lacZ fusion in the IncQ class expression vector pMP } 190 \text {, } \\
\mathrm{Cm}^{\mathrm{r}}, \mathrm{Str}^{\mathrm{r}}\end{array}$ & $\begin{array}{l}\text { Zaat et al. } 1987, \\
\text { Spaink et al. } 1987 \text { a }\end{array}$ \\
\hline pMP 280 & R. leguminosarum nodD inserted in the IncP class broad host range cloning vector $\mathrm{pMP} 92, \mathrm{Tc}^{\mathrm{r}}$ & Spaink et al. 1987a,b \\
\hline
\end{tabular}

${ }^{\mathrm{a}} \mathrm{Cm}^{\mathrm{r}}$, Rif ${ }^{\mathrm{r}}, \mathrm{Spc}^{\mathrm{r}}, \mathrm{Str}^{\mathrm{r}}$, and $\mathrm{Tc}^{\mathrm{r}}=$ chloramphenicol, rifampicin, spectinomycin, streptomycin, and tetracycline resistance, respectively; Inc $=$ plasmid incompatibility group; $\mathrm{Tn} 1831$ codes for spectinomycin and streptomycin resistance. 
the nodulation process (Boot et al. 1999; Heidstra et al. 1997). The point where mitogenic LCOs and nodulating rhizobia inhibit root hair growth in our system lies somewhere between the root hair initiation step and the elongation step. Accumulation of NodD-activating compounds, which most likely are flavonoid-like compounds, in epidermal root hair cells after addition of mitogenic LCOs or nodulating rhizobia may well influence the amount of auxin in these cells, in accordance to recent work by Mathesius (2001). This author found that different flavonoids that accumulate locally during early nodulation could strongly influence the auxin content of cells by regulating auxin breakdown by peroxidases. A local decrease in auxin content may prevent root hair elongation, especially in the presence of the ethylene inhibitor AVG. Such physiological changes also may contribute to autoregulation of nodulation (van Brussel et al. 2002).

Alternatively (or at the same time), mitogenic LCOs may directly interfere with root hair tip growth. Root hair curling and infection thread initiation, both induced by mitogenic LCOs, are based on redirection of root hair tip growth (Van Batenburg et al. 1986). Recently, it was found that one of the genes involved in root hair growth in Arabidopsis spp. encoded an NADPH oxidase, a protein that is involved in the production of reactive oxygen species (ROS) (Foreman et al. 2003) that could regulate root hair growth by the activation of $\mathrm{Ca}^{2+}$ channels. $\mathrm{Ca}^{2+}$ channels also play a role in signal transduction of mitogenic LCOs in perceptive legume root hairs (Cullimore et al. 2001). Mitogenic NodRlvIV/V[18:4,Ac] LCOs produced by $R$. leguminosarum interaction may interfere with the activity of an NADPH oxidase involved in root hair initiation and root hair growth in V. sativa subsp. nigra.

\section{MATERIALS AND METHODS}

\section{Bacterial strains.}

Data on the bacterial strains used in this study and their references is shown in Table 1.

\section{Plant assay.}

V. sativa subsp. nigra plants were grown as recently described (Van Spronsen et al 2003). In short:, after sterilization, washing, and incubation for 7 days at $4{ }^{\circ} \mathrm{C}$ and overnight germination at $28^{\circ} \mathrm{C}$, seed with roots of approximately $1.5 \mathrm{~cm}$ were transferred to dark pots (= brown glass vials which roots shielded from light) (Spaink et al. 1991). The pots contained liquid Jensen medium (Vincent 1970), buffered at pH 5.6 with $10 \mathrm{mM}$ MES buffer (ICN Biomedicals, Aurora, OH, U.S.A.) and the ethylene-biosynthesis inhibitor AVG (Sigma, Bornhem, Belgium) $(0.1 \mathrm{mg} / \mathrm{liter})$. Plants were inoculated with the appropriate $R$. leguminosarum bacteria or incubated with purified mitogenic NodRlv-IV/V[18:4,Ac] or nonmitogenic NodRlv-IV/V[18:1,Ac] LCOs (Spaink et al. 1991) and allowed to grow for the indicated time in a growth chamber at $20^{\circ} \mathrm{C}$ with $120 \mu \mathrm{E} \mathrm{s}^{-1} \mathrm{~m}^{-2}$ on the table surface (Philips TLD $50 \mathrm{w} / 83 \mathrm{HF}$ tubes); light and dark regime of 16 and $8 \mathrm{~h}$, respectively, and relative humidity, 70\%. Experiments were done with 12 plants and repeated at least three times. The concentrations of purified LCOs were calculated after determination of the molar absorption coefficient (van Brussel et al. 2002).

\section{Radioactive labeling of LCOs and TLC.}

Plants were grown as described above. To $25 \mathrm{ml}$ of growth medium, $5 \mu \mathrm{Ci}$ D- $\left[1-{ }^{14} \mathrm{C}\right]$ glucosamine $(\mathrm{GlcN}, 56 \mathrm{mCi}$ mmol-1 Amersham Pharmacia Biotech, Buckinghamshire, U.K.) was added. Growth medium was isolated 24, 48, 72, or $96 \mathrm{~h}$ after inoculation with $R$. leguminosarum RBL 5523. After centrifugation of the growth medium for $10 \mathrm{~min}$ at $15,000 \times \mathrm{g}$, radioactive-labeled LCOs were extracted from the supernatant with $25 \mathrm{ml}$ of water-saturated $n$-butanol as described previously (Spaink et al. 1991, 1992). The butanol phase was dried under vacuum and dissolved in $50 \mu \mathrm{l}$ of acetonitrilewater (1:1, vol/vol). Experiments were done with six plants and repeated at least three times.

$R$. leguminosarum RBL 5523 was grown overnight in $20 \mathrm{ml}$ of $\mathrm{B}^{-}$medium in the presence of $4 \mu \mathrm{Ci} \mathrm{D}-\left[1-{ }^{14} \mathrm{C}\right]$ glucosamine and $1 \mu \mathrm{M}$ of the nod gene-inducer naringenin at either 28 or $20^{\circ} \mathrm{C}$. Radioactive LCOs were extracted as described (Spaink et al. 1991, 1992). Volumes of $5 \mu \mathrm{l}$ were analyzed on either silica 60 TLC plate (Merck, Darmstadt, Germany) using $n$-butanolethanol-water $(5: 3: 2, \mathrm{vol} / \mathrm{vol} / \mathrm{vol})$ as the mobile phase or on octadecyl silica (ODS) TLC plates (Sigma) and acetonitrile/water (50:50, vol/vol) as the solvent. Radioactivity was detected using a phosphor imaging system of Molecular Dynamics (Sunnyvale, CA, U.S.A.) using the ImageQuant software.

\section{Assay for NodD-activating compounds.}

Plants were grown as described above. Plant root exudates $(500 \mu \mathrm{l})$ were sampled at the indicated time points and stored at $-20^{\circ} \mathrm{C}$. Induction experiments were carried out as described by Zaat and associates (1987) with modifications. The $R$. leguminosarum indicator strain RBL 5280 was grown overnight at $28^{\circ} \mathrm{C}$ in $\mathrm{B}^{-}$medium and diluted the next day to an optical density at $660 \mathrm{~nm}\left(\mathrm{OD}_{660}\right)$ of 0.03 with Jensen medium without depot. To $2.8 \mathrm{ml}$ of diluted bacteria suspension, $200 \mu \mathrm{l}$ of exudate was added and incubated overnight at $28^{\circ} \mathrm{C}$. As a control, $200 \mu \mathrm{l}$ of luteolin, with a final concentration of 200 $\mathrm{nM}$, was added to $2.8 \mathrm{ml}$ of diluted bacteria suspension. The next day, the $\mathrm{OD}_{660}$ was measured and the cells were lysed with $50 \mu \mathrm{l}$ of toluene, shaken for $30 \mathrm{~min}$ in a water bath at $40^{\circ} \mathrm{C}$, and vortexed again. Then, $200 \mu \mathrm{l}$ was added to tubes containing $1,400 \mu \mathrm{l}$ of assay buffer and $250 \mu \mathrm{l}$ of 2nitrophenyl- $\beta$-D-galactopyranoside (ONPG, Duchefa, Haarlem, The Netherlands) solution $(5 \mathrm{mg} / \mathrm{ml})$. The tubes were incubated in a water bath at $28^{\circ} \mathrm{C}$, and reactions were stopped by adding $750 \mu \mathrm{l}$ of sodium carbonate of a $1 \mathrm{M}$ solution, and $\mathrm{OD}_{420}$ was determined. The $\beta$-galactosidase activity was expressed as a percentage of the luteolin-induced activity that was set at $100 \%$.

\section{Microscopy.}

Roots were cut from the plants and kept in $50 \%$ ethanol. The root hairs were studied with an MZ 12 stereomicroscope equipped with a transmitted-light stand for bright- and darkfield viewing and a Leitz Labovert reversal microscope (Leica Microsystems, Wetzlar, Germany). Images were recorded with a DKC-5000 digital photo camera (Sony, Tokyo), converted to grayscale and corrected for brightness and contrast using Adobe Photoshop software (San Jose, CA, U.S.A.).

\section{ACKNOWLEDGMENTS}

K. J. M. Boot was supported by an NWO-STW grant (project number LBI 4572). We thank P. Hock for preparing Figures 1 to 4; and D. Rodriguez-Navarro and M. Camacho, C.J.F.A., Las Torres y Tomejil, Sevilla, Spain for providing us with seed of Vicia sativa subsp. nigra.

\section{LITERATURE CITED}

Armitage, J. P., Gallagher, A., and Johnston, A. W. B. 1988. Comparison of the chemotactic behaviour of Rhizobium leguminosarum with and without the nodulation plasmid. Mol. Microbiol. 2:743-748.

Boot, K. J. M., van Brussel, A. A. N., Tak, T., Spaink, H. P., and Kijne, J. W. 1999. Lipochitin oligosaccharides from Rhizobium leguminosarum 
bv. viciae reduce auxin transport capacity in Vicia sativa subsp. nigra roots. Mol. Plant-Microbe Interact. 12:839-844.

Cho, H. T., and Cosgrove, D. J. 2002. Regulation of root hair initiation and expansin gene expression in Arabidopsis. Plant Cell 14:3237-3253.

Cullimore J. V., Ranjeva, R., and Bono, J. J. 2001. Perception of lipo-chitooligosaccharidic Nod factors in legumes. Trends Plant Sci. 6:24-30.

Downie, J. A. 1998. Functions of rhizobial nodulation genes. Pages $387-$ 402 in: The Rhizobiaceae, Molecular Biology of Model Plant-Associated Bacteria. H. P. Spaink, A. Kondorosi, and P. J. J. Hooykaas, eds. Kluwer Academic Publishers, Dordrecht, The Netherlands.

Foreman, J., Demidchick, V., Bothwell J. H. F., Mylona, P., Miedema, H., Torres, M. A., Linstaed, P., Costa, S., Brownlee, C., Jones, J. D. G., Davies, J. M., and Dolan, L. 2003. Reactive oxygen species produced by NADPH oxidase regulate plant cell growth. Nature 422:442-446.

Heidstra, R., Yang, W. C., Yalcin, Y., Peck, S., Emons, A., Van Kammen, A., and Bisseling, T. 1997. Ethylene provides positional information on cortical cell division but is not involved in nod factor-induced root hair tip growth in Rhizobium-legume interaction. Development 124:1781-1787.

Hooykaas, P. J. J., Schnijdewindt, F. G. M., and Schilperoort, R. A. 1982. Identification of the Sym plasmid of Rhizobium leguminosarum strain 1001 and its transfer to and expression in other Rhizobia and Agrobacterium tumefaciens. Plasmid 8:73-82.

Josey, D. P., Beynon, J. L., Johnston, A. W. B., and Beringer, J. E. 1979. Strain identification in Rhizobium using intrinsic antibiotic resistance. J. Appl. Microbiol. 46:343-350.

Lerouge, P., Roche, P., Faucher, C., Maillet, F., Truchet, G., Promé, J. C. and Dénarié, J. 1990. Symbiotic host-specificity of Rhizobium meliloti is determined by a sulphated and acylated glucosamine oligosaccharide signal. Nature 344:781-784.

Mathesius, U. 2001. Flavonoids induced in cells undergoing nodule organogenesis in white clover are regulators of auxin breakdown by peroxidase. J. Exp. Bot. 52:419-426.

Mathur, J., and Hülskamp, M. 2001. Cell growth: How to grow and where to grow. Curr. Biol. 11:402-404.

Pees, E., Wijffelman, C. A., Mulders, I., van Brussel, A. A. N., and Lugtenberg, B. J. J. 1986. Transposition of Tn1831 to Sym plasmids of Rhizobium leguminosarum and Rhizobium trifolii. FEMS (Fed. Eur. Microbiol. Soc.) Microbiol. Lett. 33:165-171.

Peters, K., Frost, J. W., and Long, S. R. 1986. A plant flavone, Luteolin, induces expression of Rhizobium meliloti nodulation genes. Science 233:977-980.

Priem, W. J. E., and Wijffelman, C. A. 1984. Selection of strains cured of the Rhizobium leguminosarum Sym plasmid pRL1JI by using small bacteriocin. FEMS (Fed. Eur. Microbiol. Soc.) Microbiol. Lett. 25:247251.

Pueppke, S. G., Bolaños-Vásquez, M. C., Werner, D, Bec-Ferté, M. P., Promé, J. C., and Krishnan, H. B. 1998. Release of flavonoids by the soybean cultivars McCall and Peking and their perception as signals by the nitrogen-fixing symbiont Sinorhizobium fredii. Plant Physiol. 117:599-608.

Rahman, A., Hosokawa, S., Oono, Y., Amakawa, T., Goto, N., and Tsurumi, S. 2002. Auxin and ethylene response interactions during Arabidopsis root hair development dissected by auxin influx modulators. Plant Physiol. 130:1908-1917.

Recourt, K., Schripsema, J., Kijne, J. W., van Brussel, A. A. N., and Lugtenberg, B. J. J. 1991. Inoculation of Vicia sativa subsp. nigra roots with Rhizobium leguminosarum biovar viciae results in release of nod gene activating flavones and chalcones. Plant Mol. Biol. 16:841-852.

Redmond, J. W., Batley, M., Djordjevic, M. A., Innes, R. W., Kuempel, P. L., and Rolfe, B. G. 1986. Flavones induce expression of nodulation genes in Rhizobium. Nature 323:632-635.

Schlaman, H. R. M., Phillips, D. A., and Kondorosi, E. 1998. Genetic organization and transcriptional regulation of rhizobial nodulation genes. Pages 361-386 in: The Rhizobiaceae, Molecular Biology of Model PlantAssociated Bacteria. H. P. Spaink, A. Kondorosi, and P. J. J. Hooykaas, eds. Kluwer Academic Publishers, Dordrecht, The Netherlands.

Spaink, H. P., Aarts, A., Stacey, G., Bloemberg, G. V., Lugtenberg, B. J. J., and Kennedy, E. P. 1992. Detection and separation of Rhizobium and Bradyrhizobium Nod metabolites using thin-layer chromatography. Mol. Plant-Microbe Interact. 5:72-80.

Spaink, H. P., Okker, R. J. H., Wijffelman, C. A., and Lugtenberg, B. J. J. 1987a. Promoters in the nodulation region of the Rhizobium leguminosarum Sym plasmid pRL1JI. Plant Mol. Biol. 9:27-39.

Spaink, H. P., Sheely, D. M., van Brussel, A. A. N., Glushka, J., York, W. S., Tak, T., Geiger, O., Kennedy, E. P., Reinhold, V. N., and Lugtenberg, B. J. J. 1991. A novel highly unsaturated fatty acid moiety of lipooligosaccharide signals determines host specificity of Rhizobium. Nature $354: 125-130$

Spaink, H. P., Wijffelman, C. A., Okker, R. J. H., and Lugtenberg, B. J. J. 1989. Localization of functional regions of the Rhizobium nodD product using hybrid nodD genes. Plant Mol. Biol. 12:59-73.

Spaink, H. P., Wijffelman, C. A., Pees, E., Okker, R. J. H., and Lugtenberg, B. J. J. 1987b. Rhizobium nodulation gene nodD as a determinant of host-specificity. Nature 328:337-340.

Staehelin, C., Schultze, M., Kondorosi, E., and Kondorosi, A. 1995. Lipochitooligosaccharide nodulation signals from Rhizobium meliloti induce their rapid degradation by the host plant alfalfa. Plant Physiol. 108:1607-1614.

Stougaard, J. 2000. Regulators and regulation of legume root nodule development. Plant Physiol. 124:531-540.

Van Batenburg, F. H. D., Jonker, R., and Kijne, J. W. 1986. Rhizobium induces marked root hair curling by redirection of tip growth: a computer simulation. Physiol. Plant. 66:476-480

van Brussel, A. A. N., Bakhuizen, R., van Spronsen, P. C., Spaink, H. P., Tak, T., Lugtenberg, B. J. J., and Kijne, J. W. 1992. Induction of preinfection thread structures in the leguminous host plant by mitogenic lipo-oligosaccharides of Rhizobium. Science 257:70-72.

van Brussel, A. A. N., Tak, T., Boot, K. J. M., and Kijne, J. W. 2002. Autoregulation of root nodule formation: Signals of both symbiotic partners studied in a split-root system of Vicia sativa subsp. nigra. Mol. Plant-Microbe Interact. 15:341-349.

van Brussel, A. A. N., Tak, T., Wetselaar, A., Pees, E., and Wijffelman, C. A. 1982. Small Leguminosae as test plants for nodulation of Rhizobium leguminosarum and other Rhizobia and Agrobacteria harbouring a leguminosarum Sym plasmid. Plant Sci. Lett. 27:317325.

Van Spronsen, P. C., Tak, T., Rood, A. M. M., van Brussel, A. A. N., Kijne, J. W., and Boot, K. J. M. 2003. Salicylic acid inhibits indeterminate-type nodulation but not determinate-type nodulation. Mol. PlantMicrobe Interact. 16:83-91.

Van Workum, W. A. T., van Slageren, S., van Brussel, A. A. N., and Kijne, J. W. 1998. Role of exopolysaccharides of Rhizobium leguminosarum bv. viciae as host plant-specific molecules required for infection thread formation during nodulation of Vicia sativa. Mol. Plant-Microbe Interact. 11:1233-1241.

Vincent, J. M. 1970. A Manual for the Practical Study of Root-Nodule Bacteria. I. B. P. Handbook No. 15. Blackwell Scientific Publications, Oxford.

Zaat, S. A. J., Schripsema, J., Wijffelman, C. A., van Brussel, A. A. N., and Lugtenberg, B. J. J. 1989a. Analysis of the major inducers of the Rhizobium nodA promoter from Vicia sativa root exudate and their activity with different nodD genes. Plant Mol. Biol. 13:175-188.

Zaat, S. A. J., Wijffelman, C. A., Spaink, H. P., van Brussel, A. A. N., Okker, R. J. H., and Lugtenberg, B. J. J. 1987. Induction of the nodA promoter of Rhizobium leguminosarum sym plasmid pRL1JI by plant flavanones and flavones. J. Bacteriol. 169:198-204.

Zaat, S. A. J., van Brussel, A. A. N., Tak, T., Lugtenberg, B. J. J., and Kijne, J. W. 1989b. The ethylene-inhibitor aminoethoxyvinylglycine restores normal nodulation by Rhizobium leguminosarum biovar. viciae the 'Thick and short roots' phenotype. Planta 177:141-150. 